\title{
Effects of Chronic Fluoxetine in Animal Models of Anxiety and Depression
}

\author{
Stephanie C Dulawa', Kerri A Holick ${ }^{2}$, Brigitta Gundersen' and Rene Hen*,1,2,3 \\ 'Center for Neurobiology and Behavior, Columbia University, New York, NY, USA; '² Department of Pharmacology, Columbia University, New York, \\ NY, USA; ${ }^{3}$ Department of Psychiatry, Columbia University, New York, NY, USA
}

\begin{abstract}
The onset of the therapeutic response to antidepressant treatment exhibits a characteristic delay. Animal models sensitive to chronic, but not acute, antidepressant treatment are greatly needed for studying antidepressant mechanisms. We initially assessed four inbred mouse strains for their behavioral response to chronic treatment with the selective-serotonin reuptake inhibitor fluoxetine $(0,5,10 \mathrm{mg} / \mathrm{kg} / \mathrm{day}$ in drinking water), which is used for the treatment of mood and anxiety disorders. Only the highly anxious BALB/c strain exhibited sensitivity to fluoxetine in the forced swim test. Additionally, fluoxetine reduced locomotion in C57BL/6 and I29SvEv, but not BALB/C and DBA/2, strains. We then evaluated the effects of subchronic ( 4 days) and chronic ( $\sim 24$ days $)$ fluoxetine treatment $(0,10,18$, $25 \mathrm{mg} / \mathrm{kg} /$ day) on measures of anxiety and depression in BALB/c mice. Anxiety measures were obtained using the open field and noveltyinduced hypophagia tests. Antidepressant effects were evaluated using the forced swim test. We found $18 \mathrm{mg} / \mathrm{kg} / \mathrm{day}$ of chronic fluoxetine to be active in all three paradigms; subchronic treatment had no effect. Anxiety-related measures were reduced by $18 \mathrm{mg} / \mathrm{kg} /$ day. In the forced swim test, 10 and $18 \mathrm{mg} / \mathrm{kg} /$ day increased swimming and reduced immobility. Here we present several novel effects of chronic, but not subchronic, antidepressant treatment.

Neuropsychopharmacology (2004) 29, I 32 I-1330, advance online publication, 7 April 2004; doi: I 0. I038/sj.npp. 1300433
\end{abstract}

Keywords: BALB/c; forced swim test; novelty-induced hypophagia; open field; antidepressants

\section{INTRODUCTION}

Animal models sensitive to chronic, but not acute, antidepressant activity are much sought after tools that have remained elusive. While acute antidepressant treatment increases synaptic monoamines within minutes to hours, weeks of sustained treatment are required for induction of therapeutic effects (Blier, 2003). These longterm effects are thought to involve increases in neural plasticity and growth-related events (D'Sa and Duman, 2002). Although some acute paradigms, such as the forced swim and tail suspension tests, provide good assay models for screening antidepressant compounds, few models have been developed in which chronic, but not acute, antidepressant treatment alters behavior (Borsini et al, 2002; Cryan et al, 2002a). Of those, none have strong predictive validity and high reliability while maintaining ease of use (Bourin et al, 2001; Cryan et al, 2002a).

\footnotetext{
*Correspondence: R Hen, Center for Neurobiology and Behavior, Columbia University, PI Annex, Room 725, 722 West 168th St, New York, NY 10032, USA, Tel: + I 212543 5137; Fax: + I 2125435074 , E-mail: rh95@columbia.edu

Received 06 October 2003; revised 29 January 2004; accepted 05 February 2004

Online publication: 13 February 2004 at http://www.acnp.org/citations/ Npp02 $160403457 /$ default.pdf
}

Depression and anxiety disorders are burdensome conditions with lifetime prevalence rates of approximately 7$20 \%$ (Hirschfeld and Weisssman, 2002) and 11-27\% (Merikangas and Pine, 2002), respectively. For medical disorders of unknown pathophysiology or genetic etiology, such as anxiety and affective disorders, the emerging approach to developing an animal model is to model a single symptom or endophenotype of the disorder, rather than the entire syndrome. The behavioral measures should satisfy the criteria of being robust, reliable, and having strong predictive validity to be initially used as a new model (Geyer and Markou, 1995, 2002). Virtually all categories of anxiety and depressive disorders are responsive to treatment with selective serotonin-reuptake inhibitors (SSRIs). Due to the broad therapeutic potential of this class of antidepressant, we used the prototypical SSRI fluoxetine (Prozac $^{\mathrm{TM}}$ ) to develop animal models of chronic, but not acute, antidepressant treatment.

In the present experiments, we assessed the effects of chronic ( $\sim 24$ days) and subchronic ( $\sim 4$ days) fluoxetine treatment on measures of anxiety and depression. To assess anxiety, we used two paradigms: the open field and the novelty-induced hypophagia tests. The open field test is a classical approach/avoidance paradigm in which the novel environment concurrently evokes both anxiety and exploration (Welker, 1957; Belzung and Le Pape, 1994; Dulawa 
et al, 1999; Prut and Belzung, 2003). An increase in activity or time spent in the center of the open field indicates reductions in anxiety and/or increases in exploration (Dulawa et al, 1999). We also developed a paradigm called 'novelty-induced hypophagia', which is a modified version of previous hyponeophagia paradigms. These paradigms use the reduction in feeding that is observed when a rodent is exposed to a novel environment as an anxiety measure (Shephard and Broadhurst, 1982; Bodnoff et al, 1988). To evaluate antidepressant effects, we used the forced swim test. The forced swim test is highly reliable and has strong predictive validity for antidepressant compounds (Porsolt et al, 1977; Cryan et al, 2002a).

We hypothesized that highly emotional mouse strains, such as the BALB/c and DBA/2, might exhibit sensitivity to chronic fluoxetine treatment. Our hypothesis was based on reports that antidepressants can have profound moodaltering effects in depressed or anxious patients, but have few effects in healthy individuals (Barr et al, 1997; Gelfin et al, 1998; Geyer and Markou, 2002). The BALB/c strain has been shown to be highly emotional, or anxious, relative to other strains in many classical approach/avoidance paradigms including the open field test (Kim et al, 2002), the light/dark test (Griebel et al, 2000; Bouwknecht and Paylor, 2002), free-exploration tests (Kopp et al, 1999; Tang et al, 2002), and the novel object test (Tang et al, 2002). BALB/c mice are also comparatively anxious when evaluated for ethological measures, such as stretch-attend postures and defecation in a novel environment (Kim et al, 2002; Yilmazer-Hanke et al, 2003). The DBA2J strain is also highly anxious in a number of paradigms, including the plus maze (Yilmazer-Hanke et al, 2003) and hole-board tests (Ohl et al, 2003).

We first assessed the effects of chronic fluoxetine $(0,5$, $10 \mathrm{mg} / \mathrm{kg} /$ day) treatment in anxious (BALB/c and DBA/2) vs non-anxious (C57BL/6 and 129SvEv) mouse strains in the open field and forced swim tests. The C57BL/6 and 129SvEv strains were selected for their high frequency of use as well as their non-anxious phenotypes (Kopp et al, 1999; Kim et al, 2002; Tang et al, 2002; Ohl et al, 2003). As only the $\mathrm{BALB} / \mathrm{c}$ strain was responsive to chronic fluoxetine treatment in the strain comparison study, we then evaluated the effects of both subchronic ( $\sim 4$ days) and chronic ( $\sim 24$ days) fluoxetine $(0,10,18,25 \mathrm{mg} / \mathrm{kg} /$ day $)$ treatment in $\mathrm{BALB} / \mathrm{c}$ mice. We assessed the effects of chronic and subchronic fluoxetine treatment in the open field test, forced swim test, and the novelty-induced hypophagia test.

\section{METHODS}

\section{Subjects}

Adult male mice of four strains: BALB/cJ, DBA/2J, C57BL/6J (Jackson Laboratories, Bar Harbor, ME), and 129S6/ SvEvTac (Taconic Farms, Germantown, NY) were subjects. For the strain comparison study, mice were 3.5-4 months old and weighed $25-35 \mathrm{~g}$. For subchronic and chronic studies using the BALB/c strain, mice were approximately 2 to 3 months old and weighed 25-30 g. Mice were maintained on a $12 \mathrm{~L}: 12 \mathrm{D}$ schedule (lights on at 0600) and were housed in groups of five with same type mice. Food and water were provided ad libitum. Behavioral testing occurred during the light phase between 0600 and 1800. All animal testing was conducted in accord with the NIH laboratory animal care guidelines and with IACUC approval.

\section{Drugs}

Fluoxetine was a generous gift from Eli Lilly (Indianapolis, IN), and was delivered ad libitum in the drinking water and changed weekly. For initial strain comparison studies, the average water intake per day for each mouse strain was recorded before the experiment began. As the average daily drinking differed between the strains, separate fluoxetine solutions were prepared so that each strain would consume 0,5 , or $10 \mathrm{mg} / \mathrm{kg} /$ day of fluoxetine. For subchronic and chronic studies in BALB/c mice, 0, 10, 18, and $25 \mathrm{mg} / \mathrm{kg} /$ day fluoxetine was given, which corresponded to $0,80,160$, and $240 \mathrm{mg} / \mathrm{l}$. Fluoxetine plasma levels were determined by liquid chromatography with fluorescence detection (Suckow et $a l, 1992$ ) for chronically treated BALB/c mice. Fluoxetine was delivered in opaque bottles to protect from light.

\section{Experiments}

For the strain comparison study, 36 male mice of each strain (BALB/c, DBA/2, C57BL/6, 129SvEv), with 12 mice per dose $(0,5,10 \mathrm{mg} / \mathrm{kg} /$ day fluoxetine) were subjects for a total of 144 mice. Mice were tested in the open field and the forced swim test following chronic fluoxetine treatment. Beginning on day 30 or 33 of chronic fluoxetine treatment, mice were tested in the open field for $15 \mathrm{~min}$ on 3 consecutive days. This design was used to habituate mice to the open field, so that center measures would predominantly reflect anxiety rather than exploration by day 3 (Dulawa et al, 1999). Mice were then tested in the forced swim test on day 36 or 37.

For chronic fluoxetine studies in $\mathrm{BALB} / \mathrm{c}$ mice, 60 male $\mathrm{BALB} / \mathrm{c}$ mice with 15 per dose $(0,10,18,25 \mathrm{mg} / \mathrm{kg} /$ day fluoxetine) were tested in the open field, the forced swim test, and the novelty-induced hypophagia test. Mice were tested first in the open field for 30 min on days 19 or 20 of chronic fluoxetine treatment. Mice were then pretested and tested in the forced swim test on days 21 and 22, respectively. Animals were then allowed to adapt to being singly housed, and were trained to drink sweetened condensed milk for novelty-induced hypophagia testing on days 25-27. Home cage and novel cage testing for the novelty-induced hypophagia test occurred on days 28 and 29 , respectively, allowing a week of recovery from the forced swim test. Mice were tested first in the open field because it is the least disruptive of the four tests. Mice were then tested in the forced swim test before the novelty-induced hypophagia test because singly housing mice has been reported to prevent antidepressant effects in the forced swim test (Karolewicz and Paul, 2001).

Studies of subchronic fluoxetine were conducted using separate groups of 60 male $\mathrm{BALB} / \mathrm{c}$ mice with 15 mice per dose $(0,10,18,25 \mathrm{mg} / \mathrm{kg} /$ day fluoxetine $)$ to prevent fluoxetine treatment from exceeding 1 week. One group was tested in the open field for $30 \mathrm{~min}$ after 1 day of subchronic fluoxetine treatment. The same mice were then pretested and tested in the forced swim test after 6 and 7 days of subchronic fluoxetine treatment, respectively. A 
second group of $60 \mathrm{BALB} / \mathrm{c}$ mice were singly housed and began fluoxetine treatment (day 1). Mice were trained to consume sweetened-condensed milk on days 1-3. They were then tested in the novelty-induced hypophagia test after 4 (home) and 5 (novel) days of subchronic fluoxetine treatment.

\section{Apparatus and Procedures}

Open field test. Motor activity was quantified in four Plexiglas open field boxes $43 \times 43 \mathrm{~cm}^{2}$ (MED Associates, Georgia, VT). Two sets of 16 pulse-modulated infrared photobeams were placed on opposite walls $2.5-\mathrm{cm}$ apart to record $x-y$ ambulatory movements. Activity chambers were computer interfaced for data sampling at 100 -ms resolution. The computer defined grid lines that divided each open field into center and surround regions, with each of four lines being $11 \mathrm{~cm}$ from each wall. Dependent measures were the number of entries into the center, the distance traveled in the center, total time spent in the center, and distance traveled in the center divided by total distance traveled. Overall motor activity was quantified as the total distance traveled $(\mathrm{cm})$.

Novelty-induced hypophagia test. Mice were singly housed several days before training began. For 3 consecutive days of training, mice were presented with diluted $(1: 3$; milk: water) sweetened condensed milk (Carnation). Milk was presented in $10 \mathrm{ml}$ serological pipettes with sippers attached with parafilm. Pipettes were closed with rubber stoppers and positioned through wire cage lids. Home cage testing occurred on day 4 when mice were briefly removed from their cages to position pipets containing the milk, and testing began when mice were returned to their cages. The latency to drink and the volume consumed were recorded every $5 \mathrm{~min}$ for $30 \mathrm{~min}$. Home cage testing occurred under dim lighting (approx. 50 lux). Mice that never drank during the $30 \mathrm{~min}$ of home cage testing were eliminated from the experiment. Novel cage testing occurred on day 5 , when mice were placed into new clean cages of the same dimensions but without shavings, with pipets containing the milk positioned. Novel cage testing occurred under bright lighting (approx. 1200 lux), with white paper placed under cages to enhance aversiveness. Thus, each mouse was trained to drink milk (days 1-3), tested in its home cage (day 4), and then tested in a novel cage (day 5).

Forced swim test. We used the modified forced swim test procedure, which is more sensitive in detecting the antidepressant activity of SSRIs than the traditional forced swim test. The modifications to the test are increasing the water depth (Detke and Lucki, 1996), and using a time sampling technique to rate the predominant behavior over a 5-s interval (Cryan and Lucki, 2000; Cryan et al, 2002b). Mice were placed into plastic buckets $19 \mathrm{~cm}$ in diameter and $23 \mathrm{~cm}$ deep filled with $23-25^{\circ} \mathrm{C}$ water, and videotaped for $6 \mathrm{~min}$. Only the last $4 \mathrm{~min}$ were scored for four measures: swimming, immobility, climbing, or other. The predominant behavior was recorded every $5 \mathrm{~s}$. For chronic and subchronic fluoxetine studies in $\mathrm{BALB} / \mathrm{c}$ mice, mice were pre-exposed to the forced swim test for $6 \mathrm{~min} 24 \mathrm{~h}$ before test day to increase sensitivity for detecting antidepressant behavioral effects (Borsini et al, 1989). We used a $6 \mathrm{~min}$ rather than the traditional 15 min pretest length because we were able to observe fluoxetine's antidepressant effects with this shorter pretest duration, and thus avoided further stress to the animals.

\section{Statistical Analysis}

Open field test. For Experiment 1, two-factor ANOVAs with fluoxetine as a between-subject factor and day as a withinsubject factor were applied to five measures for each strain: time spent in the center, distance traveled in the center, center distance/total distance traveled, entries into the center, and total distance traveled. Subchronic and chronic experiments in $\mathrm{BALB} / \mathrm{c}$ mice were analyzed using one-way ANOVAs with fluoxetine as a between-subjects factor. As data deviated substantially from a normal distribution due to low activity levels of $\mathrm{BALB} / \mathrm{c}$ mice, analyses were applied to log transformed data.

When significant differences in locomotor activity were observed in the open field, ANCOVAs were applied to center measures with locomotor activity as a covariate. Remaining significant effects of fluoxetine indicate independence between measures of locomotor activity and center measures.

Novelty-induced hypophagia test. For latency scores, a maximum cutoff of $600 \mathrm{~s}$ was used. Two-factor ANOVAs with home/novel cage condition as a within-subjects factor and fluoxetine as a between-subjects factor were applied to latency values. Mice having latency difference scores (novel minus home) that were greater or less than two standard deviations from the mean were eliminated from analysis for all measures of the novelty-induced hypophagia test. For consumption data, a three-factor ANOVA with block (5 min intervals) and home/novel cage condition as within-subjects factors and fluoxetine as a between-subjects factor was used to assess whether the novel cage was sufficiently anxiogenic to reduce consumption. Two-factor ANOVAs with block as a within-subjects factor and fluoxetine as a between-subjects factor were applied separately to consumption values for the home and the novel cage.

Forced swim test. Two-factor ANOVAs with fluoxetine as a between-subjects factor and block (1 min intervals) as a within-subject factor were applied to three different measures: swimming, immobility, and climbing. When significant differences in swimming were observed, ANCOVAs were applied to the effects of fluoxetine on swimming with locomotor activity values from the open field test as a covariate. Remaining significant effects of fluoxetine indicate independence between measures of locomotor activity and swimming.

For all tests, significant main effects or interactions were resolved using post hoc ANOVAs with adjusted $P$-values and/or Newman-Keuls post hoc tests. Significance was set at $P<0.05$. 


\section{RESULTS}

\section{Strain Comparison Studies}

Open field test. Four strains of mice, BALB/c, DBA/2, C57BL/6, and 129SvEv, were tested on 3 consecutive days in the open field to assess locomotion and anxiety measures. ANOVAs revealed that $\mathrm{BALB} / \mathrm{c}$ mice showed no changes in locomotor activity, while $\mathrm{C} 57 \mathrm{BL} / 6$ and $129 \mathrm{SvEv}$ mice showed reductions in locomotor activity, and DBA/2 mice showed a trend towards increased locomotor activity in response to chronic fluoxetine treatment (Figure 1). The $10 \mathrm{mg} / \mathrm{kg} /$ day dose of fluoxetine reduced locomotor activity in $129 \mathrm{SvEv}$ mice relative to both other doses on day 1 , and relative to the $5 \mathrm{mg} / \mathrm{kg} / \mathrm{day}$ dose on day 3 . The $10 \mathrm{mg} / \mathrm{kg} /$ day dose of fluoxetine reduced locomotor activity overall in C57BL mice $(\mathrm{F}(2,33)=3.30, P=0.05)$ relative to controls. $\mathrm{DBA} / 2$ mice showed a trend $(\mathrm{F}(4,62)=2.40, P=0.06)$ for the $10 \mathrm{mg} / \mathrm{kg} / \mathrm{day}$ dose of fluoxetine to increase locomotion relative to controls on day 3 .

None of the four strains exhibited increases in center entries, time in the center, distance traveled in the center, or center/total distance traveled in response to chronic fluoxetine treatment (data not shown). In fact, chronic fluoxetine reduced center measures in $\mathrm{C} 57 \mathrm{BL} / 6$ and $129 \mathrm{SvEv}$ mice, and produced no changes in BALB/c and $\mathrm{DBA} / 2$ mice. Both doses of fluoxetine ( 5 and $10 \mathrm{mg} / \mathrm{kg} /$ day) reduced time in the center relative to control in $129 \mathrm{SvEv}$ mice $(\mathrm{F}(2,29)=4.90, P<0.01)$. Additionally, both doses of fluoxetine reduced the distance traveled in the center $(\mathrm{F}(4,58)=3.11, P<0.05)$ and center entries $(\mathrm{F}(4,58)=4.08$, $P<0.01)$ relative to controls on day 1 in $129 \mathrm{SvEv}$ mice. C57BL/6 mice also showed an overall reduction in the number of entries into the center $(\mathrm{F}(2,33)=8.00, P<0.01)$ for both doses of fluoxetine relative to control. The decrease in center measures exhibited by C57BL/6 and 129SvEv mice in response to drug was likely related to decreased locomotor activity. Indeed, ANCOVAs revealed that drug no longer had a significant effect on center measures when data were analyzed using locomotor activity as a covariate.
Furthermore, no effects of chronic fluoxetine on center/total distance traveled were found in any strain.

Forced swim test. The BALB/c was the only strain showing sensitivity to chronic treatment with fluoxetine (Figure 2). $\mathrm{BALB} / \mathrm{c}$ mice treated with the $10 \mathrm{mg} / \mathrm{kg} /$ day dose of fluoxetine showed increased swimming $(\mathrm{F}(2,33)=4.37$, $P<0.05)$ and decreased immobility $(\mathrm{F}(2,33)=3.52$, $P<0.05)$ relative to the $5 \mathrm{mg} / \mathrm{kg} /$ day dose and controls. No interactions of drug and time block were found for any measure. ANCOVA indicated that fluoxetine's effects on swimming remained significant when locomotor activity values from the open field test were used as a covariate $(\mathrm{F}(2,138)=5.96, \quad P<0.01)$. No effects of fluoxetine on climbing were observed.

\section{Chronic vs Subchronic Effects of Fluoxetine in BALB/C Mice}

Serum fluoxetine levels. Serum fluoxetine levels were assessed in $\mathrm{BALB} / \mathrm{c}$ mice receiving chronic fluoxetine treatment $(0,10,18$, and $25 \mathrm{mg} / \mathrm{kg} /$ day) (Figure 3). Fluoxetine exhibited nonlinear kinetics, indicated by a disproportionate increase in its blood concentrations with increasing doses. Serum levels for norfluoxetine $(\mathrm{ng} / \mathrm{ml})$ were $205.3 \pm 53.8,495.4 \pm 99.0$, and $1132 \pm 98.1$ for the 10 , 18 , and $25 \mathrm{mg} / \mathrm{kg} /$ day doses, respectively.

Open field test. BALB/c mice treated chronically with fluoxetine were tested in the open field for $30 \mathrm{~min}$. As in the strain comparison study, fluoxetine did not alter total locomotor activity in BALB/c mice $(\mathrm{F}(3,56)=$ $1.36, P=0.27)$. However, for the $\log$ of center entries $(\mathrm{F}(3,56)=6.85, \quad P<0.001)$, the $\log$ of center distance $(\mathrm{F}(3,56)=2.89, P<0.05)$, and the log of center distance/ log total distance traveled $(\mathrm{F}(3,56)=2.69, P=0.05)$, mice treated with $18 \mathrm{mg} / \mathrm{kg} /$ day fluoxetine exhibited significantly higher values than controls (Figure 4). For the log of center entries, mice treated with $10 \mathrm{mg} / \mathrm{kg} / \mathrm{day}$ fluoxetine also

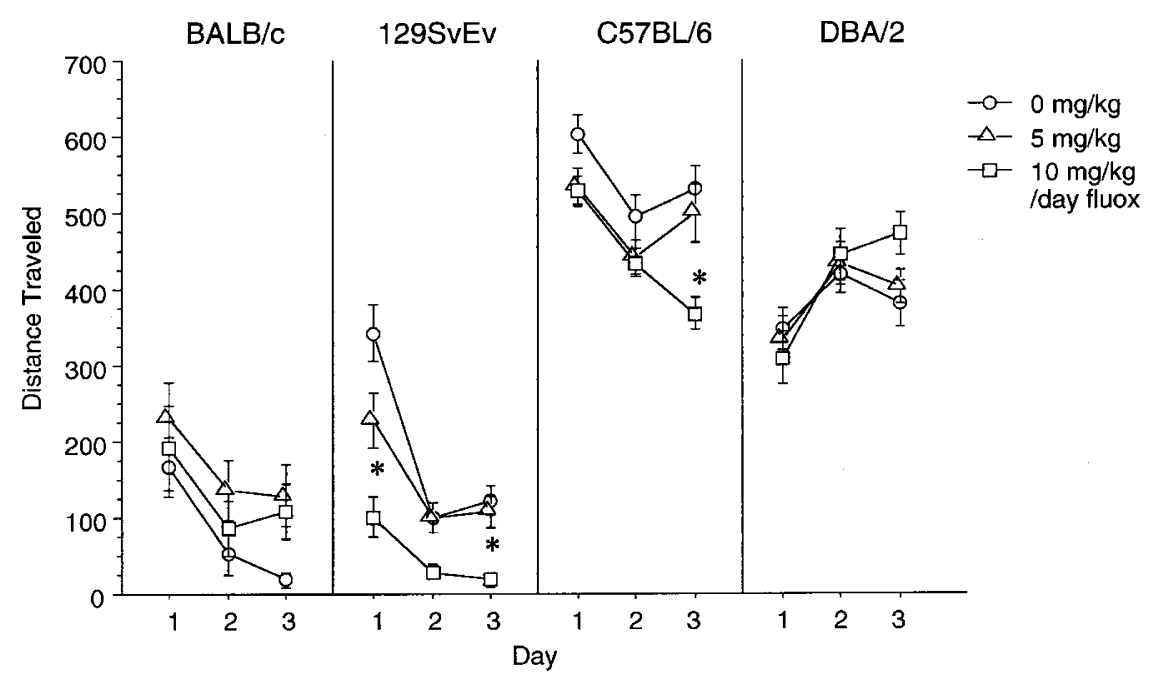

Figure I Motor activity. Total locomotor activity assessed in the open field test on 3 consecutive days is shown for BALB/c $(n=36)$, I29SvEv $(n=35)$, C57BL/6 $(n=36)$, and DBA/2 $(n=36)$ mice receiving 0,5 , or $10 \mathrm{mg} / \mathrm{kg} /$ day chronic fluoxetine. Values are means $\pm S E M$. *P $<0.05$ vs control group with ANOVA. 


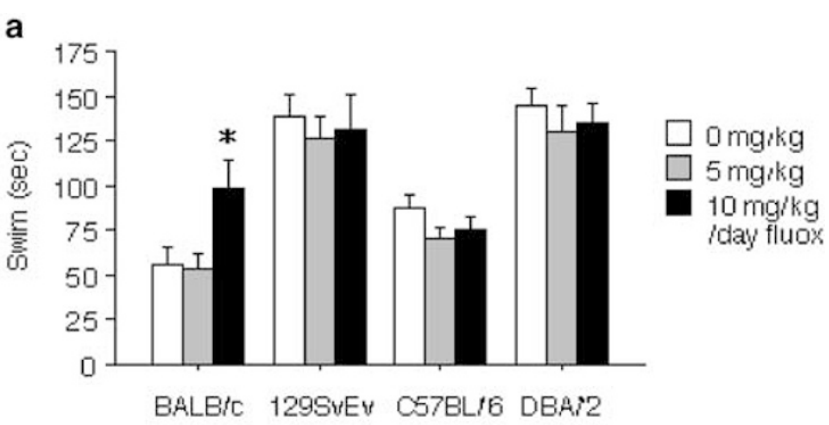

b
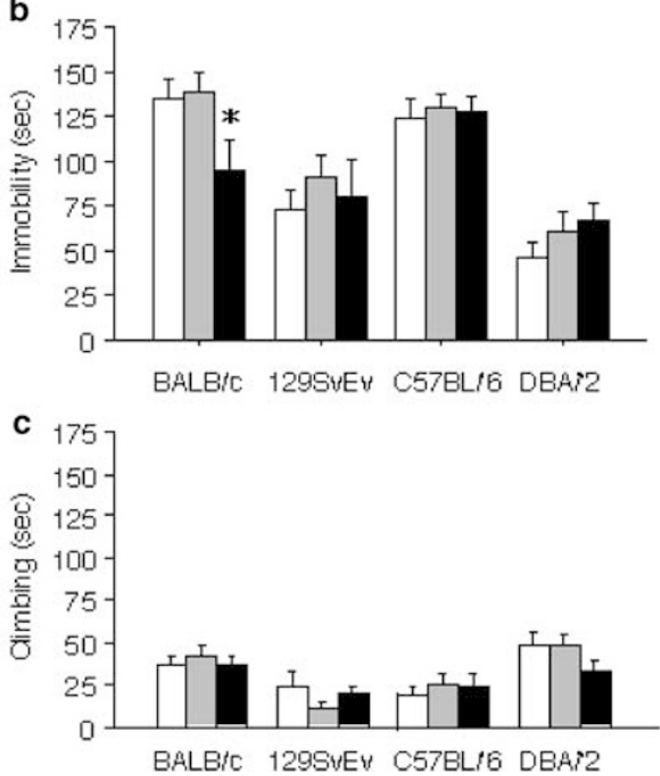

Figure 2 Forced swim test. Total time engaged in swimming (a), immobility (b), or climbing (c) are shown for BALB/c $(n=36)$, I29SvEv $(n=35), \mathrm{C} 57 \mathrm{BL} / 6(n=36)$, and DBA/2 $(n=36)$, mice receiving 0 , 5 , or $10 \mathrm{mg} / \mathrm{kg} /$ day chronic fluoxetine. Values are means \pm SEM. $* P<0.05$ vs control group with ANOVA.

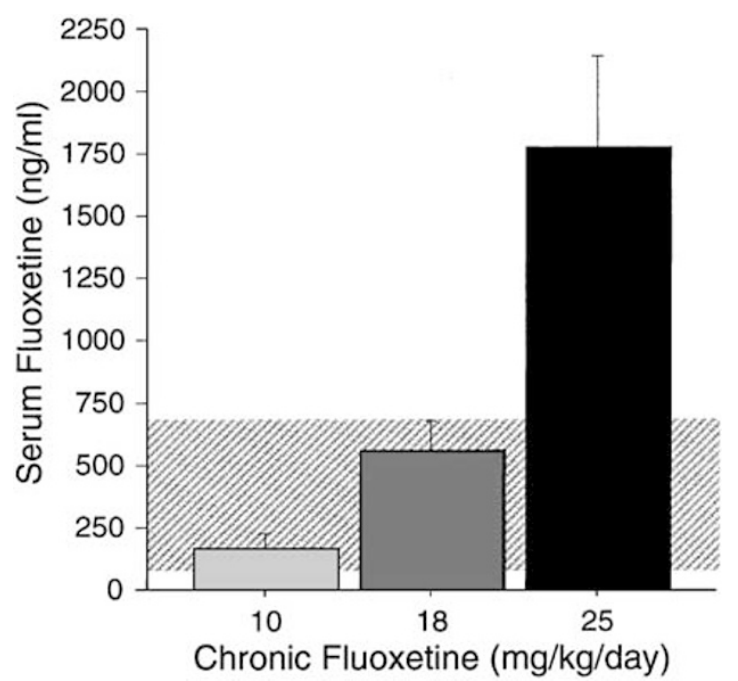

Figure 3 Plasma fluoxetine levels. Plasma fluoxetine levels are shown in $\mathrm{ng} / \mathrm{ml}$ for BALB/c mice receiving 10 , 18 , or $25 \mathrm{mg} / \mathrm{kg} /$ day chronic fluoxetine $(n=5$ per group). The shaded area shows plasma fluoxetine levels for patients taking $20-80 \mathrm{mg}$ Prozac per day. exhibited lower values than groups receiving 18 and $25 \mathrm{mg} /$ $\mathrm{kg} /$ day. Although the same trend was observed, there was no significant effect of drug on log of time in the center. Even without logarithmic transformation, mice treated with $18 \mathrm{mg} / \mathrm{kg} /$ day fluoxetine made more center entries $(\mathrm{F}(3,56)=3.07, P<0.05)$ and showed a trend for higher center/total distance values $(\mathrm{F}(3,56)=2.51, P=0.07)$ than controls, while total locomotor activity remain unaffected by all doses of drug $(\mathrm{F}(3,56)=0.86, P=0.47)$.

$\mathrm{BALB} / \mathrm{c}$ mice treated subchronically (one day) with fluoxetine showed no differences in any measures in the open field, whether data were analyzed untransformed, or following logarithmic transformation (Table 1).

Novelty-induced hypophagia. Mice were assessed for the latency to consume and the amount consumed of a familiar and palatable snack in the home cage and a novel cage. The latency of one mouse was not recorded, and three (of 60 total) mice never drank in the home cage. Chronic fluoxetine treatment reduced the latency to drink milk in the novel, but not the home cage $(\mathrm{F}(3,48)=3.87, P<0.01)$ (Figure 5a). In the novel cage, all three doses of fluoxetine reduced the latency to drink relative to control in a doserelated manner. For latency difference scores (novel minus home), control animals exhibited significantly larger difference scores than animals receiving 18 and $25 \mathrm{mg} / \mathrm{kg} /$ day fluoxetine (Figure 5a). Four animals of 56 total with latency difference scores greater or less than two standard deviations from the mean were eliminated from analysis for the novelty-induced hypophagia test.

Chronic fluoxetine treatment also attenuated another anxiety-related measure as assessed by consumption in the novel environment. Milk consumption was reduced overall in the novel environment compared to the home environment during the first $5 \mathrm{~min}(\mathrm{~F}(1,103)=11.86, P<0.001)$. Additionally, both the 18 and $25 \mathrm{mg} / \mathrm{kg} /$ day doses of fluoxetine increased milk consumption compared to the 0 and $10 \mathrm{mg} / \mathrm{kg} /$ day doses in the first block $(\mathrm{F}(15,240)=2.10$, $P<0.01$ ) in the novel cage (Figure $5 \mathrm{~b}$ ). In the home cage, the $25 \mathrm{mg} / \mathrm{kg} /$ day dose of fluoxetine increased milk consumption compared to control in the first block $(\mathrm{F}(15,245)=2.29$, $P<0.01$ ).

Subchronic (4-5 days) treatment with fluoxetine had no effect on any measure of latency. The overall latency to drink was increased in the novel cage $(F(1,47)=4.33$, $P<0.05)$, suggesting that the novel cage was anxiogenic. Similarly, milk consumption was reduced in the novel environment compared to the home condition during the first $5 \mathrm{~min}(\mathrm{~F}(1,99)=9.62, P<0.01)$. There was no effect of subchronic fluoxetine treatment on milk consumption. While ANOVA found a main effect of fluoxetine on consumption in the home cage $(\mathrm{F}(3,47)=3.57, P<0.05)$, post hoc tests found only a trend for the $25 \mathrm{mg} / \mathrm{kg} /$ day dose to increase consumption relative to control (Table 1).

Forced swim test. In the forced swim test, SSRIs decrease immobility and increase swimming, while catecholaminergic agents decrease immobility and increase climbing in rats (Cryan and Lucki, 2000; Cryan et al, 2002a, b). On test day, $\mathrm{BALB} / \mathrm{c}$ mice treated chronically with 10 and $18 \mathrm{mg} / \mathrm{kg} /$ day fluoxetine showed increases in swimming compared to mice treated with 0 and $25 \mathrm{mg} / \mathrm{kg} /$ day of fluoxetine 

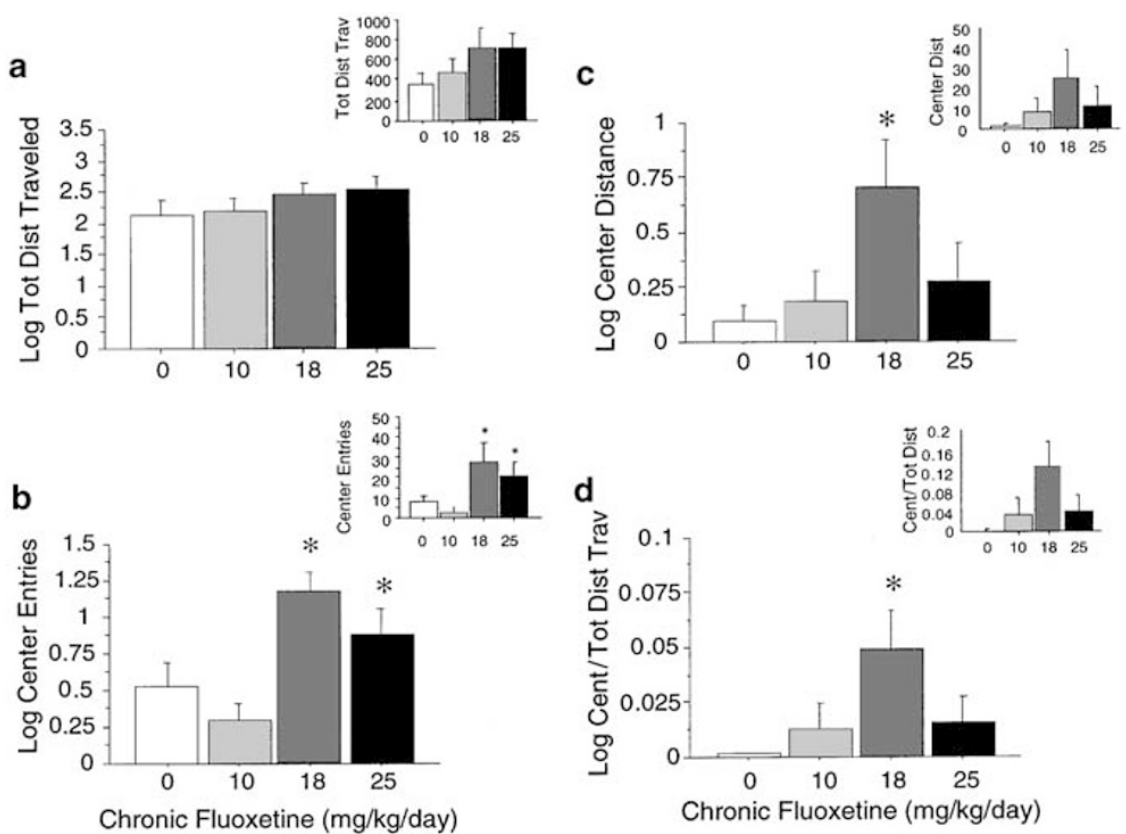

Figure 4 Open field test. Log transformed data for open field measures are shown for BALB/c mice receiving $0,10,18$, and $25 \mathrm{mg} / \mathrm{kg} / \mathrm{day}$ chronic fluoxetine ( $n=15$ per group). Log of total locomotor activity (a), log of the distance traveled in the center (b), log of entries into the center (c), and the log of center/total distance traveled (d) are shown in $\mathrm{cm}$. Untransformed data are shown in insets. Values are means \pm SEM. $* P<0.05$ vs control group with ANOVA.

Table I Behavioral Effects of Subchronic vs Chronic Fluoxetine in BALB/c Mice

\begin{tabular}{|c|c|c|c|c|c|c|c|}
\hline & & \multicolumn{3}{|c|}{ Subchronic } & \multicolumn{3}{|c|}{ Chronic } \\
\hline & & df & F value & $P$-value & df & F value & $P$-value \\
\hline \multicolumn{8}{|l|}{ Open field } \\
\hline Center entries & Drug & 3,55 & 0.56 & 0.6470 & 3,56 & 6.85 & $0.0005 *$ \\
\hline Center distance & Drug & 3,55 & 0.82 & 0.4890 & 3,56 & 2.89 & $0.0400 *$ \\
\hline Center/tot distance & Drug & 3,55 & 0.65 & 0.5840 & 3,56 & 2.69 & $0.0500 *$ \\
\hline \multicolumn{8}{|l|}{ Forced swim test } \\
\hline Swimming & Drug & 3,56 & 1.26 & 0.297 & 3,56 & 3.20 & $0.0300 *$ \\
\hline \multicolumn{8}{|l|}{ Novelty-induced hypophagia } \\
\hline Latency & Drug $\times$ cage & 3,52 & 0.57 & 0.6300 & 3,48 & 3.93 & $0.0100 *$ \\
\hline Home consumption: 0-5 min & Drug & 15,260 & 0.88 & 0.5877 & 15,245 & 2.29 & 0.0050* \\
\hline Novel consumption: $0-5$ min & Drug & 15,260 & 1.34 & 0.1770 & 15,240 & 2.10 & $0.0100 *$ \\
\hline
\end{tabular}

All dependent measures showing a statistically significant effect of chronic fluoxetine were unaltered by subchronic fluoxetine.

$(\mathrm{F}(3,56)=3.20, P<0.05) \quad$ (Figure 6a). ANCOVA indicated that fluoxetine's effects on swimming remained significant when locomotor activity values from the open field test were used as a covariate $(\mathrm{F}(3,232)=3.70, P<0.05)$. Although ANOVA indicated that chronic fluoxetine treatment did not significantly reduce immobility, planned comparisons revealed that the $10 \mathrm{mg} / \mathrm{kg} / \mathrm{day}(\mathrm{F}(1,118)=3.81, P=0.05)$ and $18 \mathrm{mg} / \mathrm{kg} /$ day $(\mathrm{F}(1,118)=4.90, P<0.05)$ doses significantly reduced immobility relative to control (Figure $6 \mathrm{~b}$ ). Mice treated with $25 \mathrm{mg} / \mathrm{kg} / \mathrm{day}$ of chronic fluoxetine also showed a trend for increased climbing relative to all other doses $(\mathrm{F}(3,56)=2.56, P=0.06)$ (Figure 6c). No interactions of drug and time block were found for any measure.

Subchronic (7 days) treatment with fluoxetine had no effect on swimming or immobility (Table 1 ). The only effect was an increase in climbing induced by the $18 \mathrm{mg} / \mathrm{kg} /$ day dose relative to the 0 dose $(\mathrm{F}(3,56)=3.34, P<0.05)$. Although catecholaminergic, but not serotonergic, agents are thought to increase climbing behavior, this hypothesis is based on results from acute, but not chronic drug studies (Cryan and Lucki, 2000; Cryan et al, 2002a,b). No interactions of drug and time block were found. 
a

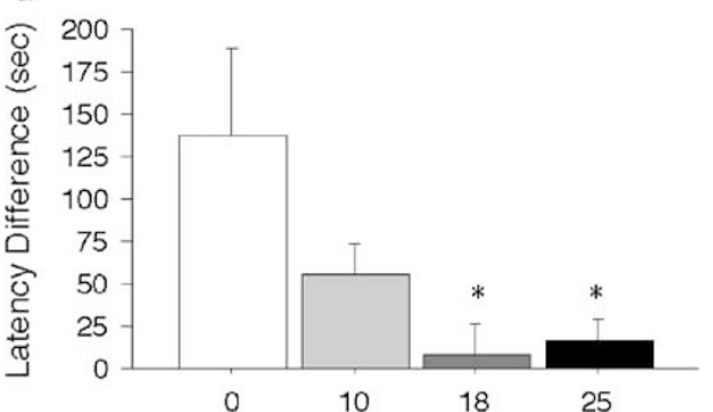

b

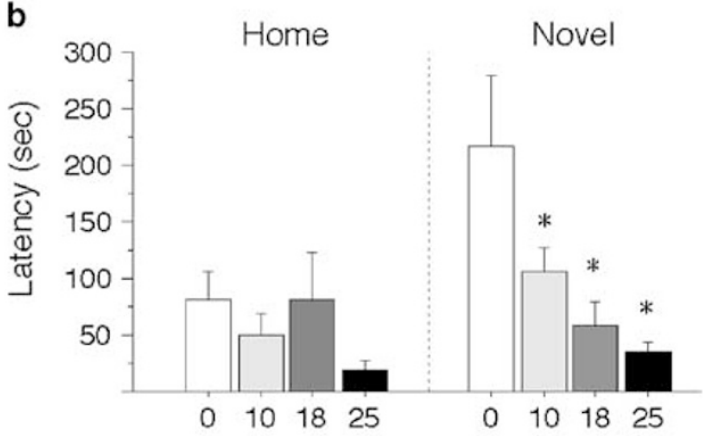

C

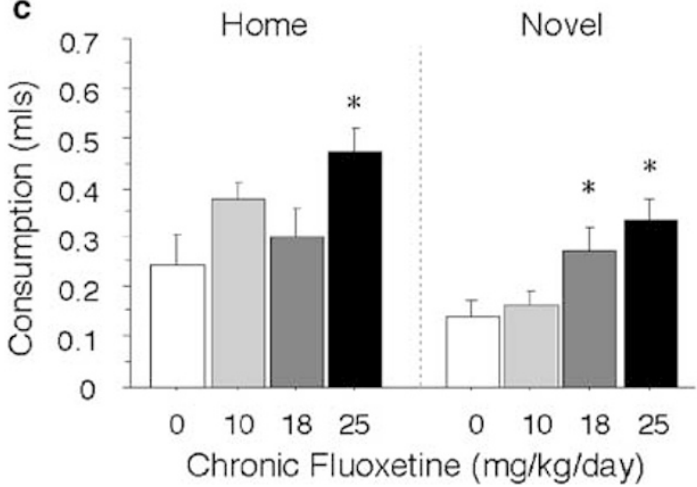

Figure 5 Novelty-induced hypophagia. The effects of a novel cage on latency to consume, and the amount consumed, of a familiar and palatable snack are shown for BALB/c mice. The difference in latency to consume in the home vs a novel cage (a), the latency to consume in the home and a novel cage (b), and the amount consumed in the first $5 \mathrm{~min}$ in the home and a novel cage (c) are shown for BALB/c mice receiving $0(n=13), 10$ $(n=13)$, $18(n=12)$, or $25(n=14) \mathrm{mg} / \mathrm{kg} /$ day chronic fluoxetine. Values are means \pm SEM. $* P<0.05$ vs control group with ANOVA.

\section{DISCUSSION}

Here we show three novel effects of chronic, but not subchronic, fluoxetine treatment on mouse behavior. In the highly emotional $\mathrm{BALB} / \mathrm{c}$ strain, chronic fluoxetine treatment ( $\sim 24$ days) increased center measures in the open field. In the novelty-induced hypophagia test, chronic fluoxetine treatment reduced the latency and increased the consumption of a palatable meal in a novel environment. In the forced swim test, chronic fluoxetine treatment increased swimming and reduced immobility. No effects of subchronic fluoxetine treatment ( $\sim 4$ days) were observed (Table 1$)$, suggesting that these models are specifically responsive to the chronic administration of fluoxetine.

The serum fluoxetine levels of chronically treated BALB/c mice were consistent with reports that fluoxetine exhibits

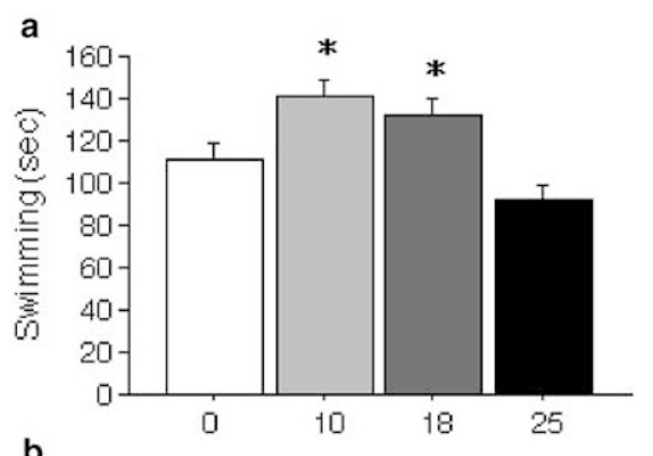

b
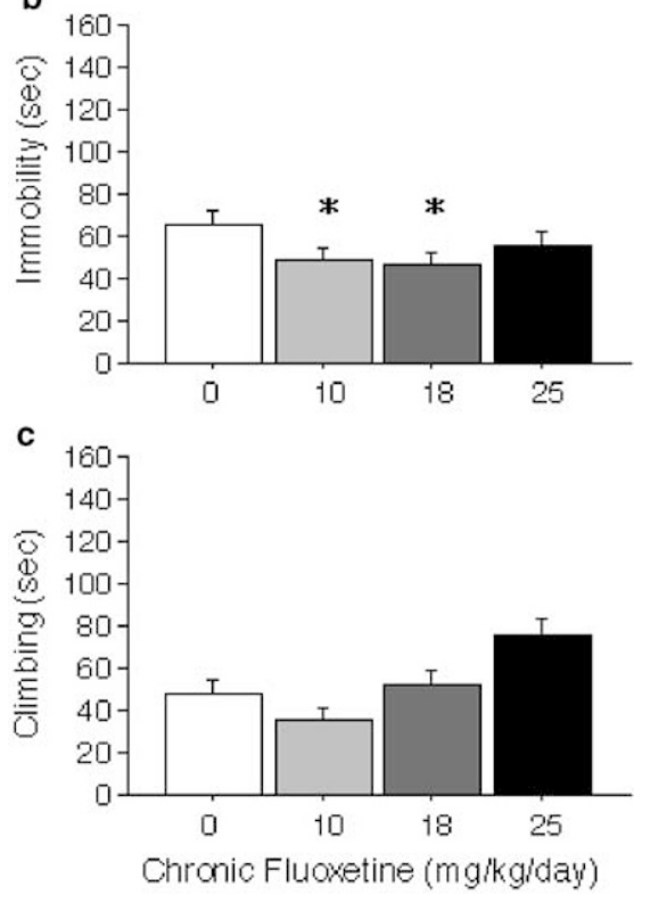

Figure 6 Forced swim test. Total time engaged in swimming (a), immobility (b), or climbing (c) are shown for BALB/c mice receiving 0,10 , 18 , or $25 \mathrm{mg} / \mathrm{kg} /$ day chronic fluoxetine ( $n=15$ per group). Values are means \pm SEM. ${ }^{*} P<0.05$ vs control group with ANOVA.

nonlinear kinetics, as indicated by a disproportionate increase in its blood concentrations after dose escalation (Caccia et al, 1990; Hiemke and Hartter, 2000) (Figure 3). Serum fluoxetine levels for the $10 \mathrm{mg} / \mathrm{kg} /$ day dose $(170.3 \pm 57.8 \mathrm{ng} / \mathrm{ml})$ were toward the bottom of the range of plasma levels found in patients taking $20-80 \mathrm{mg}$ /day Prozac (100-700 ng/ml) (Koran et al, 1996). Serum levels for the $18 \mathrm{mg} / \mathrm{kg} / \mathrm{day}$ dose $(563.4 \pm 118.4 \mathrm{ng} / \mathrm{ml})$ were toward the high end of this range. However, the $25 \mathrm{mg} / \mathrm{kg} /$ day dose of fluoxetine resulted in serum levels $(1779.2 \pm 364.9 \mathrm{ng} / \mathrm{ml})$ that were over twice the maximum of the human range. The ratio of plasma fluoxetine to norfluoxetine observed here is similar to that reported for humans (Koran et al, 1996). We have previously shown that steady state for both fluoxetine and norfluoxetine is achieved by 5 days of receiving fluoxetine in the drinking water $(10 \mathrm{mg} / \mathrm{kg} /$ day $)$, as serum levels after 5 or 90 days of treatment are equivalent (Santarelli et al, 2003).

Identification of the $\mathrm{BALB} / \mathrm{c}$ strain as sensitive to chronic fluoxetine was critical for the development of the mouse 
models presented here. Our finding that the highly anxious $\mathrm{BALB} / \mathrm{c}$ strain is sensitive to chronic fluoxetine treatment is consistent with reports that in humans, antidepressants can have profound mood-altering effects in depressed or anxious patients, but have few effects in healthy individuals (Barr et al, 1997; Gelfin et al, 1998; Geyer and Markou, 2002). It also suggests that the frequent use of mouse strains that are not anxious, such as the $\mathrm{C} 57 \mathrm{BL} / 6$, may contribute to the widespread difficulties in developing chronic antidepressant models. Inducing deficits in animals that are central features or symptoms of anxiety or depressive disorders may be essential for establishing models of antidepressant activity. For example, desipramine and low dose fluoxetine do not alter intracranial self-stimulation reward thresholds unless animals have undergone drug withdrawal (Kokkinidis et al, 1980; Markou et al, 1992; Barr et al, 2002) or chronic stress (Moreau et al, 1992). The use of a highly anxious strain, such as the BALB/c, for models of antidepressant activity offers unique advantages. Using an anxious strain avoids the time, effort, and potential variability of chronic stress paradigms, and offers a more unbiased approach for identifying novel therapeutic targets than models based on pharmacological perturbations (Thompson et al, 2003). Furthermore, using the BALB/c strain as a background for mutant mouse lines will allow the investigation of a role for the mutated genes in antidepressant action.

The strain comparison of the effects of chronic fluoxetine in the open field revealed that $129 \mathrm{SvEv}$ and C57BL/6 mice showed reduced locomotor activity to $10 \mathrm{mg} / \mathrm{kg} /$ day of fluoxetine. This reduction in locomotor activity could potentially confound other behavioral measures attempting to assess anti-anxiety or antidepressant effects of chronic fluoxetine. Thus, these two commonly used strains may be undesirable for studying the effects of chronic fluoxetine treatment. The BALB/c strain, however, exhibited no sedative effect. We do not believe that the lack of a sedative effect in the BALB/c strain is due to a floor effect, because the higher doses of fluoxetine appear to modestly increase locomotor activity in both experiments (nonsignificant) (Figures 2 and 4). The BALB/c was the only strain to respond to chronic fluoxetine in the forced swim test (Figure 2). The lack of effect of chronic fluoxetine treatment on locomotor activity together with the increase in swimming and decrease in immobility observed in the forced swim test indicated that the $\mathrm{BALB} / \mathrm{c}$ strain was the most suitable strain for assessing the effects of chronic fluoxetine. It should be noted that these strain differences may result from pharmacokinetic differences, and that one or more strains may respond to doses of fluoxetine not tested here.

Anxiety measures of the open field test have been suggested to be insensitive to antidepressant treatment by a substantial literature (Prut and Belzung, 2003). Here, we observed that $\mathrm{BALB} / \mathrm{c}$ mice receiving chronic, but not subchronic, fluoxetine showed increases in center entries, distance traveled in the center, and center/total distance traveled at the $18 \mathrm{mg} / \mathrm{kg} /$ day dose, with no change in overall locomotor activity. These findings strongly suggest that $18 \mathrm{mg} / \mathrm{kg} /$ day of chronic fluoxetine decreases anxiety and/or increases exploration (Dulawa et al, 1999) in BALB/c mice. Although a large number of studies have found no effect of antidepressants in the open field (Prut and Belzung, 2003), few have evaluated the effects of chronic treatment in anxious animals. To our knowledge, the effects of chronic antidepressant treatment on open field measures in BALB/C mice have not been previously reported.

The forced swim test has strong predictive validity, high reliability, and is easy to use (Porsolt et al, 1977; Cryan et al, 2002a). However, acute antidepressant-like effects in the forced swim test are likely to reflect the initial events elicited by antidepressants rather than the progressive changes that are likely to accompany chronic antidepressant treatment. Studies comparing the acute and chronic effects of SSRIs in the forced swim test have reported comparable behavioral effects at the two timepoints both in rats (Reneric et al, 2002; Kelliher et al, 2003) and in mice (Conti et al, 2002). In addition, C57BL/6 mice have been shown to be sensitive to chronic treatment with tricyclic antidepressants in the forced swim test, although acute or subchronic timepoints were not evaluated (Alcaro et al, 2002). Only one report has found antidepressant effects of chronic, but not acute, low dose fluoxetine or desipramine treatment in rats (Detke et al, 1997). Furthermore, the dual 5-HT/NA reuptake inhibitor milnacipran has been shown to increase climbing when given subchronically, and increase both climbing and swimming when given chronically in rats (Reneric et al, 2002). Here, we observed that while subchronic fluoxetine had no effect, chronic treatment with 10 and $18 \mathrm{mg} / \mathrm{kg} /$ day fluoxetine increased swimming and reduced immobility in both experiments in $\mathrm{BALB} / \mathrm{C}$ mice (Figures 1 and 6). ANCOVA showed that the nonsignificant increases in locomotion induced by fluoxetine found in the open field (Figures 2 and 4) were not responsible for the increases in swimming in either experiment. A trend for an increase in climbing induced by chronic treatment with $25 \mathrm{mg} / \mathrm{kg} /$ day fluoxetine may have resulted from a loss of specificity for the serotonergic system of this high dose (Figure 3). Previous reports have shown that acute injection of $10 \mathrm{mg} / \mathrm{kg}$ fluoxetine reduces immobility in BALB/c mice (Lucki et al, 2001). The present lack of effect of subchronic fluoxetine treatment should not have resulted from lower plasma fluoxetine levels compared to chronically treated mice, since we have previously found steady-state blood levels to be achieved by day 5 with administration of fluoxetine in the drinking water (Santarelli et al, 2003). Rather, the sensitivity of BALB/c mice to acute $10 \mathrm{mg} / \mathrm{kg}$ fluoxetine treatment (Lucki et al, 2001) likely results from the sharp peak levels of drug produced by injection. We administered fluoxetine in the drinking water to avoid the stress to animals and the sharp peak drug levels produced by daily injection.

$\mathrm{BALB} / \mathrm{c}$ mice exhibited sensitivity to chronic, but not subchronic, treatment with fluoxetine treatment in the novelty-induced hypophagia test. The novel cage was anxiety-provoking, as the latency to drink was increased and the first $5 \mathrm{~min}$ of milk consumption was decreased relative to behavior in the home cage. In the novel cage, all three doses reduced the latency to consume milk relative to control. Additionally, the 18 and $25 \mathrm{mg} / \mathrm{kg} /$ day doses decreased difference scores for latency (home vs novel) relative to control, and increased the first $5 \mathrm{~min}$ of milk consumption in the novel environment. Although the $25 \mathrm{mg} / \mathrm{kg} /$ day dose also increased consumption in the first 
$5 \mathrm{~min}$ in the home cage, this dose resulted in serum levels that are over twice the maximum levels found in patients taking 20-80 mg/day Prozac ${ }^{\mathrm{TM}}$ (Koran et al, 1996). The novelty-induced hypophagia paradigm might also assess fluoxetine's effects on hedonic processes in addition to anxiety. The intake of palatable fluids, including sucrose and saccharin solutions, has been used as a measure of reward sensitivity (Willner, 1997; Le Pen et al, 2002). In such paradigms, reduced drinking is thought to reflect anhedonia, a core symptom of depression in the current diagnostic system, the Diagnostic and Statistical Manual of Mental Disorders, Fourth Edition (American Psychiatric Association, 1994). Due to the high palatability of sweetened-condensed milk, the novelty-induced hypophagia paradigm might assess anhedonia in addition to anxiety.

The novelty-induced hypophagia paradigm offers advantages over existing hyponeophagia-based models. Although current models use extensive food deprivations (24h for mice) to induce feeding behavior (Shephard and Broadhurst, 1982; Bodnoff et al, 1988; Bilkei-Gorzo et al, 2002; Santarelli et al, 2003), we have found that these deprivation periods can induce variable hunger levels as assessed by latency in identical batches of mice (data not shown). In the present work and that of Merali et al (2003), the use of a familiar and highly palatable snack makes food deprivations unnecessary. Additionally, the present use of a novel cage (Merali et al, 2003) rather than an open field (Bodnoff et al, 1988; Bilkei-Gorzo et al, 2002; Santarelli et al, 2003) works equally well while conserving space, and may minimize any potentially confounding locomotor effects. Finally, both latency and consumption measures are applied in both the home and novel conditions in the novelty-induced hypophagia test, while other paradigms assess only latency (Bodnoff et al, 1988; Bilkei-Gorzo et al, 2002; Merali et al, 2003), or latency in the novel cage and consumption in the home cage (Santarelli et al, 2003). The exclusive use of latency scores has several drawbacks in hyponeophagiabased paradigms. Aside from not exhibiting normal distributions, latency values in the home condition are invariably very small compared to those in the novel condition. Thus, while home cage latency scores are used to control for potential effects of drug treatments on hunger or food preferences, floor effects may often preclude this control. On the other hand, consumption scores are not vulnerable to floor effects (Figure 5). Ideally, both latency and consumption scores should be assessed in the home and novel conditions.

Our findings introduce three novel effects of chronic, but not subchronic, antidepressant treatment in the anxious $\mathrm{BALB} / \mathrm{c}$ strain. These models are easy to use, and appear reliable. Animal models exhibiting sensitivity to antidepressant compounds and the time course of their effects represent powerful tools for mechanistic studies into the antidepressant response. Studies are currently underway to further pharmacologically validate these models.

\section{ACKNOWLEDGEMENTS}

This work was supported by the National Institute on Drug Abuse (R01 DA09862), the National Institute of Mental Health (R01 MH068542-1), (P50 MH50733), and the
National Alliance for Research on Schizophrenia and Depression (NARSAD). SC Dulawa was supported by an individual postdoctoral National Research Service Award (F32-MH65791-01A1).

\section{REFERENCES}

Alcaro A, Cabib S, Ventura R, Puglisi-Allegra S (2002). Genotypeand experience-dependent susceptibility to depressive-like responses in the forced-swimming test. Psychopharmacology (Berlin) 164: 138-143.

American Psychiatric Association (1994). Diagnostic and Statistical Manual of Mental Disorders, 4th edn. American Psychiatric Association: Washington, DC.

Barr AM, Markou A, Phillips AG (2002). A 'crash' course on psychostimulant withdrawal as a model of depression. Trends Pharmacol Sci 23: 475-482.

Barr LC, Heninger GR, Goodman W, Charney DS, Price LH (1997). Effects of fluoxetine administration on mood response to tryptophan depletion in healthy subjects. Biol Psychiatry 41: 949-954.

Belzung C, Le Pape G (1994). Comparison of different behavioral test situations used in psychopharmacology for measurement of anxiety. Physiol Behav 56: 623-628.

Bilkei-Gorzo A, Racz I, Michel K, Zimmer A (2002). Diminished anxiety- and depression-related behaviors in mice with selective deletion of the Tac1 gene. J Neurosci 22: 10046-10052.

Blier P (2003). The pharmacology of putative early-onset antidepressant strategies. Eur Neuropsychopharmacol 13: 57-66.

Bodnoff SR, Suranyi-Cadotte B, Aitken DH, Quirion R, Meaney MJ (1988). The effects of chronic antidepressant treatment in an animal model of anxiety. Psychopharmacology (Berlin) 95: 298-302.

Borsini F, Lecci A, Sessarego A, Frassine R, Meli A (1989). Discovery of antidepressant activity by forced swimming test may depend on pre-exposure of rats to a stressful situation. Psychopharmacology (Berlin) 97: 183-188.

Borsini F, Podhorna J, Marazziti D (2002). Do animal models of anxiety predict anxiolytic-like effects of antidepressants? Psychopharmacology (Berlin) 163: 121-141.

Bourin M, Fiocco AJ, Clenet F (2001). How valuable are animal models in defining antidepressant activity? Hum Psychopharmacol 16: 9-21.

Bouwknecht JA, Paylor R (2002). Behavioral and physiological mouse assays for anxiety: a survey in nine mouse strains. Behav Brain Res 136: 489-501.

Caccia S, Cappi M, Fracasso C, Garattini S (1990). Influence of dose and route of administration on the kinetics of fluoxetine and its metabolite norfluoxetine in the rat. Psychopharmacology (Berlin) 100: $509-514$.

Conti AC, Cryan JF, Dalvi A, Lucki I, Blendy JA (2002). cAMP response element-binding protein is essential for the upregulation of brain-derived neurotrophic factor transcription, but not the behavioral or endocrine responses to antidepressant drugs. J Neurosci 22: 3262-3268.

Cryan JF, Lucki I (2000). Antidepressant-like behavioral effects mediated by 5 -Hydroxytryptamine(2C) receptors. J Pharmacol Exp Ther 295: 1120-1126.

Cryan JF, Markou A, Lucki I (2002a). Assessing antidepressant activity in rodents: recent developments and future needs. Trends Pharmacol Sci 23: 238-245.

Cryan JF, Page ME, Lucki I (2002b). Noradrenergic lesions differentially alter the antidepressant-like effects of reboxetine in a modified forced swim test. Eur J Pharmacol 436: 197-205.

D'Sa C, Duman RS (2002). Antidepressants and neuroplasticity. Bipolar Disord 4: 183-194. 
Detke MJ, Johnson J, Lucki I (1997). Acute and chronic antidepressant drug treatment in the rat forced swimming test model of depression. Exp Clin Psychopharmacol 5: 107-112.

Detke MJ, Lucki I (1996). Detection of serotonergic and noradrenergic antidepressants in the rat forced swimming test: the effects of water depth. Behav Brain Res 73: 43-46.

Dulawa SC, Grandy DK, Low MJ, Paulus MP, Geyer MA (1999). Dopamine D4 receptor-knock-out mice exhibit reduced exploration of novel stimuli. J Neurosci 19: 9550-9556.

Gelfin Y, Gorfine M, Lerer B (1998). Effect of clinical doses of fluoxetine on psychological variables in healthy volunteers. Am J Psychiatry 155: 290-292.

Geyer M, Markou A (1995). Animal models of psychiatric disorders. In: Bloom F, Kupfer D (eds). Psychopharmacology: The Fourth Generation of Progress. Raven Press: New York. pp 787-798.

Geyer M, Markou A (2002). The role of preclinical models in the development of psychotropic drugs. In: Davis K, Charney D, Coyle J, Nemeroff C (eds). Neuropsychopharmacology: The Fifth Generation of Progress. Lippincott Williams \& Wilkins: Philadelphia. pp 446-455.

Griebel G, Belzung C, Perrault G, Sanger DJ (2000). Differences in anxiety-related behaviours and in sensitivity to diazepam in inbred and outbred strains of mice. Psychopharmacology (Berlin) 148: 164-170.

Hiemke C, Hartter S (2000). Pharmacokinetics of selective serotonin reuptake inhibitors. Pharmacol Ther 85: 11-28.

Hirschfeld R, Weisssman M (2002). Risk factors for major depression and bipolar disorder. In: Davis K, Charney D, Coyle J, Nemeroff C (eds). Neuropsychopharmacology: The Fifth Generation of Progress. Lippincott Williams \& Wilkins: Philadelphia. pp 1018-1025.

Karolewicz B, Paul IA (2001). Group housing of mice increases immobility and antidepressant sensitivity in the forced swim and tail suspension tests. Eur J Pharmacol 415: 197-201.

Kelliher P, Kelly JP, Leonard BE, Sanchez C (2003). Effects of acute and chronic administration of selective monoamine re-uptake inhibitors in the rat forced swim test. Psychoneuroendocrinology 28: 332-347.

Kim S, Lee S, Ryu S, Suk J, Park C (2002). Comparative analysis of the anxiety-related behaviors in four inbred mice. Behav Processes 60: 181-190.

Kokkinidis L, Zacharko RM, Predy PA (1980). Post-amphetamine depression of self-stimulation responding from the substantia nigra: reversal by tricyclic antidepressants. Pharmacol Biochem Behav 13: 379-383.

Kopp C, Vogel E, Rettori MC, Delagrange P, Guardiola-Lemaitre B, Misslin R (1999). Effects of melatonin on neophobic responses in different strains of mice. Pharmacol Biochem Behav 63: 521-526.

Koran LM, Cain JW, Dominguez RA, Rush AJ, Thiemann S (1996). Are fluoxetine plasma levels related to outcome in obsessivecompulsive disorder? Am J Psychiatry 153: 1450-1454.

Le Pen G, Gaudet L, Mortas P, Mory R, Moreau JL (2002). Deficits in reward sensitivity in a neurodevelopmental rat model of schizophrenia. Psychopharmacology (Berlin) 161: 434-441.

Lucki I, Dalvi A, Mayorga AJ (2001). Sensitivity to the effects of pharmacologically selective antidepressants in different strains of mice. Psychopharmacology (Berlin) 155: 315-322.
Markou A, Hauger RL, Koob GF (1992). Desmethylimipramine attenuates cocaine withdrawal in rats. Psychopharmacology (Berlin) 109: 305-314.

Merali Z, Levac C, Anisman H (2003). Validation of a simple, ethologically relevant paradigm for assessing anxiety in mice. Biol Psychiatry 54: 552-565.

Merikangas K, Pine D (2002). Genetic and other vulnerability factors for anxiety and stress disorders. In: Davis K, Charney D, Coyle J, Nemeroff C (eds). Neuropsychopharmacology: The Fifth Generation of Progress. Lippincott Williams \& Wilkins: Philadelphia. pp 868-882.

Moreau JL, Jenck F, Martin JR, Mortas P, Haefely WE (1992). Antidepressant treatment prevents chronic unpredictable mild stress-induced anhedonia as assessed by ventral tegmentum self-stimulation behavior in rats. Eur Neuropsychopharmacol 2: 43-49.

Ohl F, Roedel A, Binder E, Holsboer F (2003). Impact of high and low anxiety on cognitive performance in a modified hole board test in C57BL/6 and DBA/2 mice. Eur J Neurosci 17: 128-136.

Porsolt RD, Bertin A, Jalfre M (1977). Behavioral despair in mice: a primary screening test for antidepressants. Arch Int Pharmacodyn Ther 229: 327-336.

Prut L, Belzung C (2003). The open field as a paradigm to measure the effects of drugs on anxiety-like behaviors: a review. Eur $J$ Pharmacol 463: 3-33.

Reneric JP, Bouvard M, Stinus L (2002). In the rat forced swimming test, chronic but not subacute administration of dual 5-HT/NA antidepressant treatments may produce greater effects than selective drugs. Behav Brain Res 136: 521-532.

Santarelli L, Saxe M, Gross C, Surget A, Battaglia F, Dulawa S et al (2003). Requirement of hippocampal neurogenesis for the behavioral effects of antidepressants. Science 301: 805-809.

Shephard RA, Broadhurst PL (1982). Hyponeophagia and arousal in rats: effects of diazepam, 5-methoxy- $N, N$-dimethyltryptamine, d-amphetamine and food deprivation. Psychopharmacology (Berlin) 78: 368-372.

Suckow RF, Zhang MF, Cooper TB (1992). Sensitive and selective liquid-chromatographic assay of fluoxetine and norfluoxetine in plasma with fluorescence detection after precolumn derivatization. Clin Chem 38: 1756-1761.

Tang X, Orchard SM, Sanford LD (2002). Home cage activity and behavioral performance in inbred and hybrid mice. Behav Brain Res 136: 555-569.

Thompson MR, Li KM, Clemens KJ, Gurtman CG, Hunt GE, Cornish JL et al (2003). Chronic fluoxetine treatment partly attenuates the long-term anxiety and depressive symptoms induced by MDMA ('Ecstasy') in rats. Neuropsychopharmaco$\log y$, doi: $10.1038 /$ sj.npp.1300347.

Welker W (1957). 'Free' versus 'forced' exploration of a novel situation by rats. Psychol Rep 3: 95-108.

Willner P (1997). Validity, reliability and utility of the chronic mild stress model of depression: a 10-year review and evaluation. Psychopharmacology (Berlin) 134: 319-329.

Yilmazer-Hanke DM, Roskoden T, Zilles K, Schwegler H (2003). Anxiety-related behavior and densities of glutamate, GABAA, acetylcholine and serotonin receptors in the amygdala of seven inbred mouse strains. Behav Brain Res 145: 145-159. 